\title{
Perceived Academic Stress Among University Undergraduates in Sri Lanka
}

\author{
S.M.N. Praveeni ${ }^{1} \&$ H.M.A.J. Herath ${ }^{2}$ \\ ${ }^{1}$ Department of Business Management \\ Faculty of Business Studies \& Finance \\ Wayamba University of Sri Lanka \\ Kuliyapitiya \\ SRI LANKA \\ ${ }^{2}$ ICT Center, Wayamba University of Sri Lanka \\ Kuliyapitiya \\ SRI LANKA \\ praveeni@wyb.ac.lk1,$\underline{\text { akila@wyb.ac.lk² }}$
}

\begin{abstract}
The purpose of the study was to investigate the levels of Perceived Academic Stress (PAS) among undergraduate students in Sri Lanka. Systematic random sampling was used to select 497 undergraduate students from the universities to participate in the study. Data on PAS were collected with the aid of the Perceived Academic Stress Scale (PASS) which was adapted from Cohen (1994) and revalidated for the study. Data were collected through previously validated questionnaire and were analyzed with descriptive and inferential statistics. The PAS levels of the respondents were compared on the basis of gender and level of study. The hypotheses formulated for the study were tested at 0.05 level of significance. The findings revealed that undergraduate students reported higher academic stress levels and negatively related with the Academic Performance (AP). It is important that students should be counseling and trained to manage stress effectively otherwise it can adversely influence their AP.
\end{abstract}

Keywords: Academic Performance, Perceived Academic Stress, University Undergraduates, Sri Lanka

\section{INTRODUCTION}

Stress has become a significant topic in academic circle as well as in our society. Many scholars in the field of behavioural science have carried out extensive research on stress and its outcomes and concluded that the topic needed more attention (Rees \& Redfern, 2000; Ellison, 2004; Ongori \& Agolla, 2008; Agolla, 2009). Stress in academic institutions can have both positive and negative consequences if not well managed (Tweed et al., 2004; Stevenson \& Harper, 2006). 
Academic stress refers to the unpleasant situations that occur due to the many demands made on the students or learners in the form of examinations, maintaining healthy and academic lives, competing with peers, meeting the academic expectations of teachers and parents as well as own academic expectations. Bisht (as cited in Lal,2014), defined PAS as demands related to academics that tax or exceed the available resources (internal and external) as cognitively viewed by the student involved. According to her, PAS reflects perceptions of an individual's academic frustration, academic conflict, academic pressure and academic anxiety.

Education is the most powerful path in acquiring knowledge, skills and nurturing positive attitudes. Proper educational level enhances productivity of any country. University education enhances the human capital of the country. If students drop out from the universities, they face difficulties in finding suitable jobs from the labour market. This leads to other social problems such as youth frustration, stress and anti-governmental activities. On the other hand, this situation hinders the development of the labour market and ultimately it affects Previous empirical studies

Previous empirical studies show that some undergraduate students significantly experience stress (Brown et al., 1999). First-year university students were found to be particularly prone to stress (Towbes \& Cohen, 1996; Pancer et al., 2000; Wintre \& Yaffe, 2000) and experience high levels of stress (Wintre \& Yaffe, 2000) due to the college life transition (Towbes \& Cohen, 1996). Many of them face culture shock as university life is different from school life. Failing to cope with the stressors during the transition may cause deterioration of AP and increase of psychological distress (Dwyer \& Cummings, 2001). The increase in stress during the first year predicted the decrease of overall adjustment and lower grade point average (GPA) (Wintre \& Yaffe, 2000). Students tend to lose self-confidence having to establish new social relations and at the same time trying to cope with the increasing academic demands (Tao et. al., 2000; Dwyer \& Cummings, 2001).

Many researches were conducted to assess the relationship between stress and AP of undergraduate students and it is found that stress affects students' AP (Elliot et al., 2005; Choi et al.,2007). Students complained of feeling stressed academically when it comes to facing exams and grade competition and having too much information to study yet insufficient time to master the knowledge (Carveth et al., 1996). Bennett (2003) reported a similar finding that stress is significantly correlated with poor AP in his study of business undergraduates. Nonetheless, no any clear-cut evidences on how PAS impact on students AP in the Sri Lankan context. The need to embark on this study is thus justified. 
Thereby, the aim of this paper is to examine and evaluate the level of PAS and relationship with AP of university Undergraduates in Sri Lanka.

\section{LITERATURE REVIEW}

AP is the outcome of education; the extent to which a student, teacher or institution has achieved their educational goals (Annie, Howard \& Mildred, 1996). Usually, university undergraduate AP is expressed in terms of GPA that is the mean of marks from weighted course units contributing to the assessment of the final degree programme. Self-reported GPA which is not only as an indicator of student learning but also as a predictor of AP and other important life outcomes (Helsper \& Eynon, 2010).

Academic performance is affected by several factors, whether internal or external (Bello \& Gumarao, 2016). Stress is one of the factors that affect the AP of students.

The processes and variables that drive the experience of stress have received considerable attention in psychological research (Lazarus, 1993). According to the transactional theory of stress (Lazarus \& Folkman,1984), stress reactions are the result of the interaction of personal variables and environmental variables. Stress can be defined as "an unfavorable person-environment relationship" (Lazarus, 1993) and is perceived when the situational demands are taxing or exceeding the resources of the individual. Cognitive appraisal is a central mediator between environmental demands and stress reactions and refers to a process in which individuals "constantly evaluate the significance of what is happening for their wellbeing" (Lazarus, 1993).

Stress is a part of life for most college students. A national survey in 2013 found that $82.8 \%$ of students reported feeling overall stress during the last year (ACHANCH,2013). University students might experience high stress due to academic commitments, financial pressures and lack of time management skills. Stress occurs when one perceives that they cannot cope with the demands of a situation (Lazarus, 1966). Stress is perceived in different ways and may mean different to different individuals. It is perceived as situations that cause individuals to feel tension, pressure, or negative emotions including anxiety and anger. Moreover, other people define stress as the response to existing situations, which includes physiological, emotional and behavioural changes (Bernstein et al. 2008). When stress is perceived negatively or becomes excessive, it can affect both health and AP (Campbell \& Svenson, 1992) and can hurt students (Amirkhan, 1998; Covington, 1997). Moreover, if the pressure is prolonged and perceived as unmanageable, these experiences have been shown to elicit helplessness, depression and stress (Carver \& Scheier, 1994), thereby placing the academic futures of some students in jeopardy (Marcos \& Tillema, 2006). A considerable number of studies have been conducted to investigate the effect of stress factors on the grade point average (GPA) of university students (Calderon et al., 2001; Hammer et al., 1998; Hatcher et al., 1991; Kelly et al., 2001; Trockel et al., 
2000; Quaye et al., 2005; Watering \& Rijt, 2006).

A study conducted by Crego et al., (2016) stated that academic stress might compromise students' performance. Another study conducted by Kötter et al., (2017) mentioned that increased stress leads to decreasing performance, increasing stress. With this, stress is revealed to have a significant relationship with AP.

\section{METHODS}

The study aimed to assess the PAS, and its relationship to students' AP. To determine the relationship between the variables, the method employed in the study was a descriptive-correlation approach. The study applied the quantitative design utilizing the questionnaire for data collection.

\subsection{Conceptual Framework}

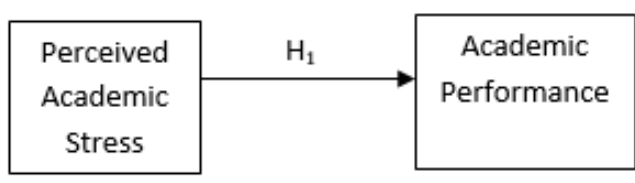

\section{Figure 1. Conceptual Framework}

\subsection{Population and Sampling}

The population of the study was the 3rd year university undergraduates who are enrolled to the management faculties which is the second-largest student's enrollment to the universities in Sri Lanka(N=5196) (Sri Lanka University Statistics, 2017). For the study, all the management faculties student enrollment has been listed in descending order (the highest to the lowest). Among the listed faculties researcher randomly selected the first four highest management faculty student enrollment as the basis in selecting the sample. According to Creswell (2009); Creswell and Plano Clark (2017) followed by the crosssectional survey, distribution of the questionnaire was conducted and yielded 497 responses from the targeted 600 potential respondents which constitutes $82 \%$ response rate. According to Roth \& BeVier (1994) the minimum acceptable level of response rate is $80 \%$. Thereby, the sample obtained within this study was an adequate representation of the total population.

\subsection{Measurements of research Constructs}

The instruments used for the study were the Perceived Stress Scale (PSS) by Cohen (1994). The Perceived Stress Scale (PSS) is a scale constructed by Cohen (1994) and is the most widely used psychological instrument for measuring stress perception. It consists of 10 items and is answered through a five-point Likert scale.

A study was conducted by $\mathrm{Lu}$ et al., (2017) to test its validity. The internal consistency reliability was .85 , measured by Cronbach's alpha. Meanwhile, the test-retest reliability coefficient was .7. It was concluded that the scale exhibited satisfactory psychometric properties.

The outcome of the study was the AP of the university undergraduates which was measured through AP proficiency scale (students' ability to perform academic tasks and solve 
problems) which is a four-item scale, used in the study by Yu et al., (2010), who adapted it from Chao et al., (1994) (e.g. I am confident about the adequacy of my academic skills and abilities, I have performed academically as well as I anticipated I would) with responses this time being a five-point Likert scale ranging from 1 (strongly disagree) to 5 (strongly agree).

\subsection{Methods of Data Collection}

In the process of accomplishing and achieving the essential findings of the study in determining the PAS and their relationship to the AP of students, preset up questionnaires were distributed to the respondents. Questionnaires were an efficient data collection mechanism when the researcher knew exactly what is required and how to measure the variables of interest. Questionnaires can be administered personally, mailed to the respondents or electronically distributed (Sekaran, 2006).

The resulting data obtained from the respondents were entered into SPSS software and the Descriptive statistics of the responses to the survey are presented with percentages of responses displayed. The descriptive statistics provide summaries about the sample's answers to each of the questions as well as measures of variability (or spread) and central tendency.

This study's main objective is to assess PAS and their relationship with the students' AP. Hence, the Correlation Analysis was conducted.

\section{RESULTS}

\subsection{Respondents Profile}

Respondent profile of the respondents formed the preliminary analysis. This is shown in Table 1.

Table1. Respondent Profile

\begin{tabular}{lcc}
\hline Profile & Frequency & Percentage \\
\hline Gender & & \\
Male & 210 & 42 \\
Female & 287 & 58 \\
Level of the & & \\
Study & & \\
Level 1 & 140 & 28 \\
Leve1 2 & 130 & 26 \\
Leve1 3 & 120 & 24 \\
Leve1 4 & 107 & 22 \\
Residence & & \\
Home & & 25 \\
Hostel & & 50 \\
Boarding & & 13 \\
Other & & 2 \\
Working & & \\
Yes & & 27 \\
No & & \\
& & \\
\hline
\end{tabular}

Source: Survey results

Table 1 shows that out of four hundred and ninety-seven students who participated in the study, 58\% were females while $42 \%$ were females. This indicates that the number of female participants in the study was a dominant fraction than that of their male counterparts. The majority of the participants were in Level 1 (28\%), whereas Level 2 had (26\%) participants and Level 4 had the least number of participants (22\%). 
Majority of the students are in university studies and they do their academic studies in the university premises whereas $25 \%$ of the sample come university from their home. It is also noted that only $27 \%$ of students are working while they engage with office work.

\subsection{Validity and Reliability}

In determining the internal consistency of constructs in the model, Cronbach's alpha and KMO and Bartlett's test were used in line with recommendations from Hair et al. (2017) and Kline (2015). Table 2 shows the results on the internal consistency measures of the reflective model.

Table 2. Construct Validity and Reliability

\begin{tabular}{lccc}
\hline Constructs & $\begin{array}{c}\text { Cronbach } \\
\text { Alpha }\end{array}$ & $\begin{array}{c}\text { KMO } \\
\text { value }\end{array}$ & $\begin{array}{c}\text { Bartlett's } \\
\text { Test }\end{array}$ \\
\hline PAS & 0.797 & 0.683 & 0.000 \\
AP & 0.867 & 0.804 & 0.000 \\
\hline
\end{tabular}

Source: Survey results

The values obtained from Cronbach's for the reflective model shows that the model achieved reliability standards as the value of Cronbach's Alpha greater than 0.7 is considered reliable (Nunnally, 1978). According to table 2 , values for the KMO test were above 0.5 and all the values for Bartlett's test indicated below 0.05 which is confirmed the validity requirements of the data set. The KMO test was used to verify the sampling adequacy for the analysis.

\subsection{Univariate Analysis}

The table 3 shows the indicators of stress represented by statements based on the Perceived Stress Scale (Cohen, 1994).

Table 3. PAS Analysis

Indicators Mean Interpretation

In the last month, how 3.05 High often have you been upset because of something that happened unexpectedly? In the last month, how often have you felt that you were unable to control the important things in your life?

In the last month, how often have you felt nervous and "stressed"?

In the last month, how often have you felt confident about your ability to handle your personal problems?

In the last month, how often have you felt that things were going your way?

In the last month, how often have you found that you could not cope with all the things that you had to do?

In the last month, how often have you been able to control irritations in your life? 3.75 High

\subsection{High}

3.10 High

3.45 High

3.02 High

High 


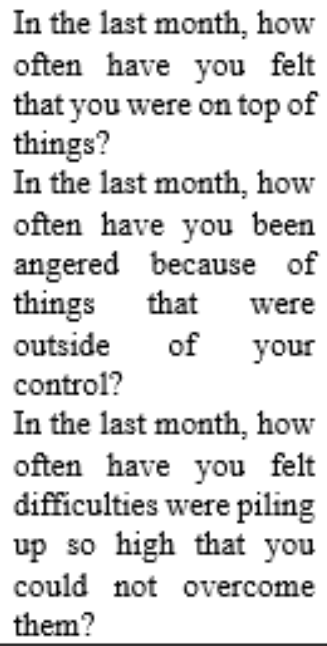

In the last month, how often have you felt that you were on top of things?

In the last month, how often have you been angered because of things that were outside of your control?

In the last month, how often have you felt difficulties were piling up so high that you could not overcome them?

Source: Survey results

The data from Table 3 revealed that the respondents attained high mean scores of 2.99 to 3.75 . It is noted that the mean of the responses from indicators 4, 5, 7, and 8 was reversed as they are positively stated items, as instructed by the scale.

Table 4. AP Analysis

\begin{tabular}{lll}
\hline Indicators & Mean & Interpretation \\
\hline I am confident about & 3.51 & High \\
the adequacy of my & & \\
academic skills and \\
abilities \\
I feel competent 3.48 & High \\
conducting my course & \\
assignments \\
I feel learned how to 3.50 & High \\
successfully perform \\
my coursework in an \\
efficient manner \\
I have performed 3.37 \\
academically as I \\
anticipated I would
\end{tabular}

Source: Survey results

According to the numeric expressions in table 4, All the mean values are above 0.3 which indicates that the average academic performance of the students are at a satisfactory level. $52 \%$ of the sample was confident on the adequacy of their academic skills and abilities while only $2 \%$ strongly disagreed with their adequacy level of academic skills. $54 \%$ of the sample have learned how to successfully perform their coursework efficiently and $46 \%$ have performed academically as they anticipated they would. However, only $21 \%$ did not perform academically as anticipated. Further, more than $40 \%$ of students are competent in conducting their course assignments.

\subsection{Bivariate Analysis}

Correlations between the constructs are as follows. The objective of the correlation analysis is to measure the degree to which two constructs are related.

Table 5. Correlation Analysis

\begin{tabular}{llll}
\hline Relationship & $\begin{array}{l}\text { P- } \\
\text { Value }\end{array}$ & $\begin{array}{l}\text { Pearson } \\
\text { Correlation }\end{array}$ & Correlation \\
\hline PAS -AP & 0.00 & -5.36 & Negative \\
\hline
\end{tabular}

Source: Survey results

Results reported in Table 5 shows that correlations among the PAS and AP and correlation coefficient was statistically significant at $\mathrm{p}<.05$. The relationship between stress and AP is negative ( $\mathrm{r}=-5.36)$. This finding is in line with the past researches (Choi, Abbott, Arthur \& Hill, 2007; Rafidah, Azizah \& Noraini, 2007). Accordingly, $\mathrm{H}_{1}$ is accepted.

Thereby, it is highlighted that higher level of PAS will lead to decrease the 
AP as there is a negative relationship between PAS and AP.

\section{DISCUSSION AND CONCLUSION}

Stress has always been an issue among undergraduate students and past research finds stress to be significantly correlated to AP. This research is carried out to discover the stress levels of the undergraduate students in a local university. Besides ensuring that the students developed in both cognitive and psychological aspects, this study also helps in considering the need of designing stress interventions for the students. From this present research, undergraduate students were found to be having moderate vulnerability to stress and academic stressors topped the sources of stress. There was a significant negative relationship identified between PAS and AP. This is important for the discovery of the latest state of psychological well-being and new sources of stress among undergraduate students. Students can be guided to reduce their stress levels as this can enhance their AP.

\section{REFERENCES}

Agolla, J.E. and Ongori, H., 2009. An assessment of academic stress among undergraduate students: The case of University of Botswana.

Amirkhan, J.H., 1998. Attributions as predictors of coping and distress. Personality and Social Psychology Bulletin, 24(9), pp.1006-1018.
Annie, W., Howard, W.S. and Mildred, $\quad$ M.W., 1996. Achievement and ability testsdefinition of the domain, educational measurement.

Asadzadeh, A., Kötter, T., Salehi, P. and Birkmann, J., 2017. Operationalizing a concept: The systematic review of composite indicator building for measuring community

disasterresilience. Internationl

journal of disaster risk reduction, 25, pp.147-162.

Bello, D.L. and Gumarao, M., 2016. Stress, Coping Strategies, and Academic Performance of Dentistry Students. Adventist University of the Philippines, p.37.

Bennett, J., 2003. Teaching and learning science: A guide to recent research and its applications. A\&C Black.

Bernstein, E.F., Freedom-2 LLC, 2008. Tissue fillers and methods of using the same. U.S. Patent Application 12/026,457.

Brown, S.J., Health Hero Network Inc, 1999. Method for treating medical conditions using a microprocessor-based video game. U.S. Patent 5,918,603.

Campbell, R.L., Svenson, L.W. and Jarvis, G.K., 1992. Perceived level of stress among university undergraduate students in Edmonton, Canada. Perceptual and motor skills, 75(2), pp.552554. 
Carver, C.S. and Scheier, M.F., 1994. Situational coping and coping dispositions in a stressful transaction. Journal of personality and social psychology, 66(1), p.184.

Carveth, J.A., Gesse, T. and Moss, N., 1996. Survival strategies for nurse-midwifery students. Journal of NurseMidwifery, 4l(1), pp.50-54.

Chao, G.T., O'Leary-Kelly, A.M., Wolf, S., Klein, H.J. and Gardner, P.D., 1994. Organizational socialization: Its content and consequences. Journal of Applied psychology, 79(5), p.730.

Choi, Y.B., Abbott, T.A., Arthur, M.A. and Hill, D.N., 2007. Toward a future wireless classroom paradigm. International Journal of Innovation and learning, 4(1), pp.14-25.

Choi, Y.B., Abbott, T.A., Arthur, M.A. and Hill, D.N., 2007. Toward a future wireless classroomparadigm. International Journal of Innovation and learning, 4(1), pp.14-25.

Cohen, A.D., 1994. Assessing language ability in the classroom.

Covington, M., Aprili, M., Paraoanu, E., Greene, L.H., Xu, F., Zhu, J. and Mirkin, C.A., 1997. Observation of surface-induced broken time-reversal symmetry in $\begin{array}{lllllll}\mathrm{YBa} & 2 & \mathrm{Cu} & 3 & \mathrm{O} & 7 & \text { tunnel }\end{array}$ junctions. Physical review letters, 79(2), p.277.
Creswell, J.W. and Clark, V.L.P., 2017. Designing and conducting mixed methods research. Sage publications.

Creswell, J.W., 2009. Mapping the field of mixed methods research.

Dwyer, A.L. and Cummings, A.L., 2001. Stress, self-efficacy, social support, and coping strategies in university students. Canadian Journal of Counselling and Psychotherapy, 35(3).

Gotelli, N.J. and Ellison, A.M., 2004. A primer of ecological statistics (Vol. 1). Sunderland: Sinauer Associates.

Hair Jr, J.F., Sarstedt, M., Ringle, C.M. and Gudergan, S.P., 2017. Advanced issues in partial least squares structural equation modeling. saGe publications.

Hatcher, P.J. and Quinn, M.J., 1991. Data-parallel

programming on MIMD computers (Vol. 90, No. 77). Mit Press.

Helsper, E.J. and Eynon, R., 2010. Digital natives: where is the evidence?. British educational research journal, 36(3), pp.503520.

Hughes-Hammer, C., Martsolf, D.S. and Zeller, R.A., 1998. Depression and codependency in women. Archives of Psychiatric Nursing, 12(6), pp.326-334. 
Hung, W.L., Xie, Y., Vijaykrishnan, N., Addo-Quaye, C., Theocharides, T. and Irwin, M.J., 2005, March. Thermal-aware floorplanning using genetic algorithms. In Sixth international symposium on quality electronic design (isqed'05) (pp. 634-639). IEEE.

Jackson, L.E., Calderon, F.J., Steenwerth, K.L., Scow, K.M. and Rolston, D.E., 2003. Responses of soil microbial processes and community structure to tillage events and implications for soil quality. Geoderma, 114(3-4), pp.305-317.

Jangid, R.S. and Kelly, J.M., 2001. Base isolation for near-fault motions. Earthquake engineering \& structural dynamics, 30(5), pp.691-707.

Kline, R.B., 2015. Principles and practice of structural equation modeling. Guilford publications.

Kobus, C., Crego, J. and Senellart, J., 2016. Domain control for neural machine translation. arXiv preprint arXiv:1612.06140.

Lazarus, R.S. and Folkman, S., 1984. Stress, appraisal, and coping. Springer publishing company.

Lazarus, R.S., 1966. Psychological stress and the coping process.

Lu, L., Guo, X. and Zhao, J., 2017. A unified nonlocal strain gradient model for nanobeams and the importance of higher order terms. International Journal of
Engineering Science, 119, pp.265-277.

Marcos, J.J.M. and Tillema, H., 2006. Studying studies on teacher reflection and action: An appraisal of research contributions. Educational Research Review, 1(2), pp.112132.

Nunnally, J. C. (1978). Psychometric theory (2nd ed.). New York: McGraw-Hill.

Ongori, H. and Agolla, J.E., 2008. Occupational stress in organizations and its effects on organizational performance. Journal of Management Research, 8(3), pp.123-135.

Pancer, S.M., Hunsberger, B., Pratt, M.W. and Alisat, S., 2000. Cognitive complexity of expectations and adjustment to university in the first year. Journal of Adolescent Research, 15(1), pp.38-57.

Rafidah, K., Azizah, A., Norzaidi, M.D., Chong, S.C., Salwani, M.I. and Noraini, I., 2009. Stress and academic performance: Empirical evidence from university students. Academy of Educational Leadership Journal, 13(1), p.37.

Rees, C.J. and Redfern, D., 2000. Recognising the perceived causes of stress-a training and development perspective. Industrial and commercial Training. 
Roth, P.L. and BeVier, C.A., 1998. Response rates in $\mathrm{HRM} / \mathrm{OB}$ survey research: Norms and correlates, 1990-1994. Journal of Management, 24(1), pp.97-117.

Setterstrom, J.A., Tice, T.R., Jacob, E., Reid, R.H., Van Hamont, J., Boedecker, E.C., Jeyanthi, R., Friden, P., Roberts, F.D., McQueen, C.E. and Bhattacharjee, A., 2005. Therapeutic treatment and prevention of infections with a bioactive material (s) encapuslated within a biodegradable-bio-compatable polymeric matrix. U.S. Patent $6,902,743$.

Smith, C.A., Haynes, K.N., Lazarus, R.S. and Pope, L.K., 1993. In search of the" hot" cognitions: Attributions, appraisals, and their relation to emotion. Journal of personality and social psychology, 65(5), p.916.

Stevenson, A. and Harper, S., 2006. Workplace stress and the student learning experience. Quality Assurance in Education.

Tao, F., Yokozawa, M., Xu, Y., Hayashi, Y. and Zhang, Z., 2006. Climate changes and trends in phenology and yields of field crops in China, 19812000. Agricultural and Forest Meteorology, 138(1-4), pp.82-92.
Towbes, L.C. and Cohen, L.H., 1996. Chronic stress in the lives of college students: Scale development and prospective prediction of distress. Journal of youth and adolescence, 25(2), pp.199-217.

Trockel, M.T., Barnes, M.D. and Egget, D.L., 2000. Health-related variables and academic performance among first-year college students: Implications for sleep and other behaviors. Journal of American college health, 49(3), pp.125-131.

Tweed, S.A., Skowronski, D.M., David, S.T., Larder, A., Petric, M., Lees, W., Li, Y., Katz, J., Krajden, M., Tellier, R. and Halpert, C., 2004. Human illness from avian influenza H7N3, British Columbia. Emerging infectious diseases, 10(12), p.2196.

Van de Watering, G. and van der Rijt, J., 2006. Teachers' and students' perceptions of assessments: A review and a study into the ability and accuracy of estimating the difficulty levels of assessment items. Educational Research Review, 1(2), pp.133-147.

Wintre, M.G. and Yaffe, M., 2000. First-year students' adjustment to university life as a function of relationships with parents. Journal of adolescent research, 15(1), pp.9-37. 